\title{
Beck x Roberts: Comparativos do Diagrama do Metrô de Londres
}

\author{
Beck x Roberts: London's Underground Diagram Comparisons
}

\author{
Joaquim Redig
}

Design de Informação, Cartografia, Sistemas de Transporte, Mobilidade, Urbanismo
Information Design, Cartography, Transport Systems, Mobility, Urbanism
Este artigo foi originalmente dirigido à disciplina Design e Visualização da Informação, ministrada pelo Prof. André Monat no curso de Doutorado em Design da ESDI-UERJ, Escola Superior de Desenho Industrial da Universidade do Estado do Rio de Janeiro, em 2013, a partir da proposta do professor de se examinar a pertinência da estrutura radial proposta por Maxwell J. Roberts para o design de mapas de redes de transporte. No artigo, procuro demonstrar que, por ser uma forma padrão pré-convencionada e abstrata, não se baseando especificamente na relação visual analógica com o objeto representado -a rede geo-espacial do sistema de transporte, variável para cada cidade- a estrutura radial, apesar da originalidade da proposta, ainda não se mostra capaz de superar a funcionalidade do sistema ortogonal/diagonal projetado por Harry Beck para o assim chamado Diagrama do metrô londrino, que, partindo do código mais universal e ancestral de orientação que é a Rosa dos Ventos, se baseia nos eixos dos percursos. Por isso, este sistema se tornou um paradigma mundial no campo do Design de Informação.

This article was originally directed to the discipline Design and Information Visualization, lectured by Prof. André Monat in the Doctorate Design course at ESDI-UERJ, Superior School of Design of the Rio de Janeiro State University, in 2013. It departed from the professor's proposition to examine the pertinence of the radial structure proposed by Maxwell J. Roberts for the design of transportation network maps. In this article I try to demonstrate that, being an abstract pre-established pattern shape that is not specially based on the analogical visual relationship to the represented object -the geo-spatial network of the transport system, variable in each city- the radial structure, apart from the originality of its proposition, has not still be able to overcome the functionality of the orthogonal/diagonal system proposed by Harry Beck to London's Underground so called Diagram, which, departing from the most universal and ancestral direction code, the Compass Rose, is based upon the path's axes. For this reason, this system has turned into an worldwide paradigm in the Information Design field.

\section{Objetivo}

O objetivo desta análise é avaliar o sistema de design radial proposto pelo professor de psicologia ("lecturer in psychology") da Universidade 
de Essex (Inglaterra) Maxwell J. Roberts, aplicado no mapa do metrô de Londres, publicado em 2013 pelo periódico inglês The Guardian, comparativamente ao sistema proposto pelo desenhista de engenharia ("engineering draughtsman") da companhia do metrô londrino Harry Beck em 1931, em uso desde 1933, que aqui chamo de "cardeal" por ser baseado nos Pontos Cardeais. A análise leva em conta a informação original que se quer transmitir com o Diagrama, que se resume à compreensão da rede e dos percursos possíveis dentro dela.

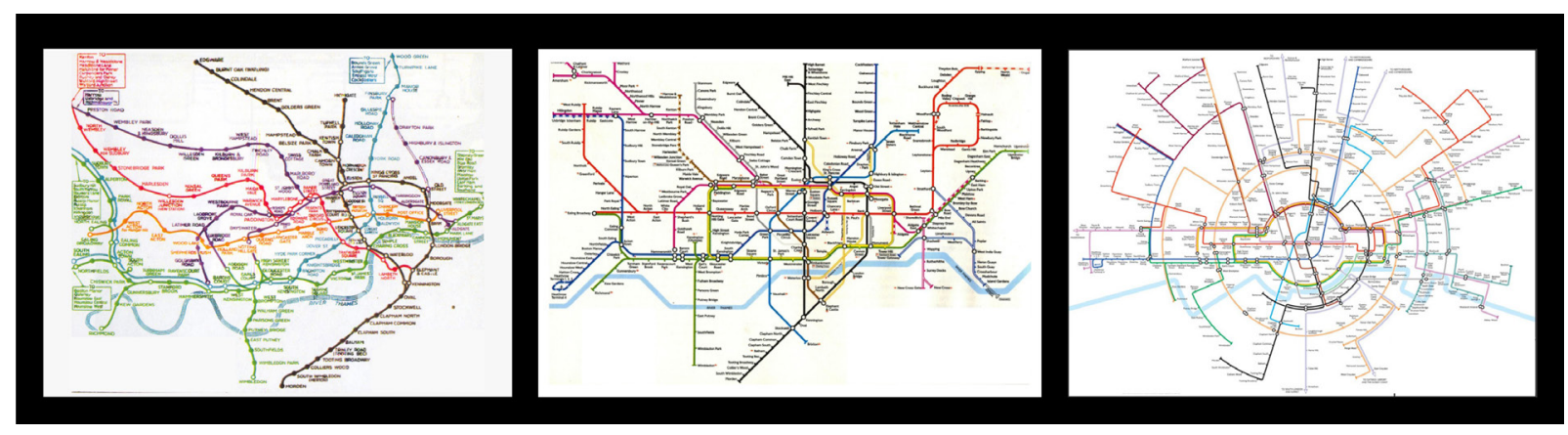

Figura 1 Os três sistemas aplicados no mapa do metrô de Londres: à esquerda o sistema cartográfico, no centro o sistema de Harry Beck e à direita o de Maxwell J. Roberts (Fontes indicadas a seguir)

\section{Premissas}

1. Parto do princípio que todo design deve ser inovador - o que não significa ser apenas diferente, mas resolver um problema até então não resolvido.

2. A idéia urbanística de um pólo central em torno do qual giram outros pontos de interesse, como configurado por Roberts, me parece pertinente a toda cidade. Mesmo conjuntos urbanos sinuosos, como a Zona Sul do Rio de Janeiro, teem algo de radial - embora não circular.

3. Neste sentido, a proposta radial é bem-vinda. Resta-nos empregá-la onde seja útil. 


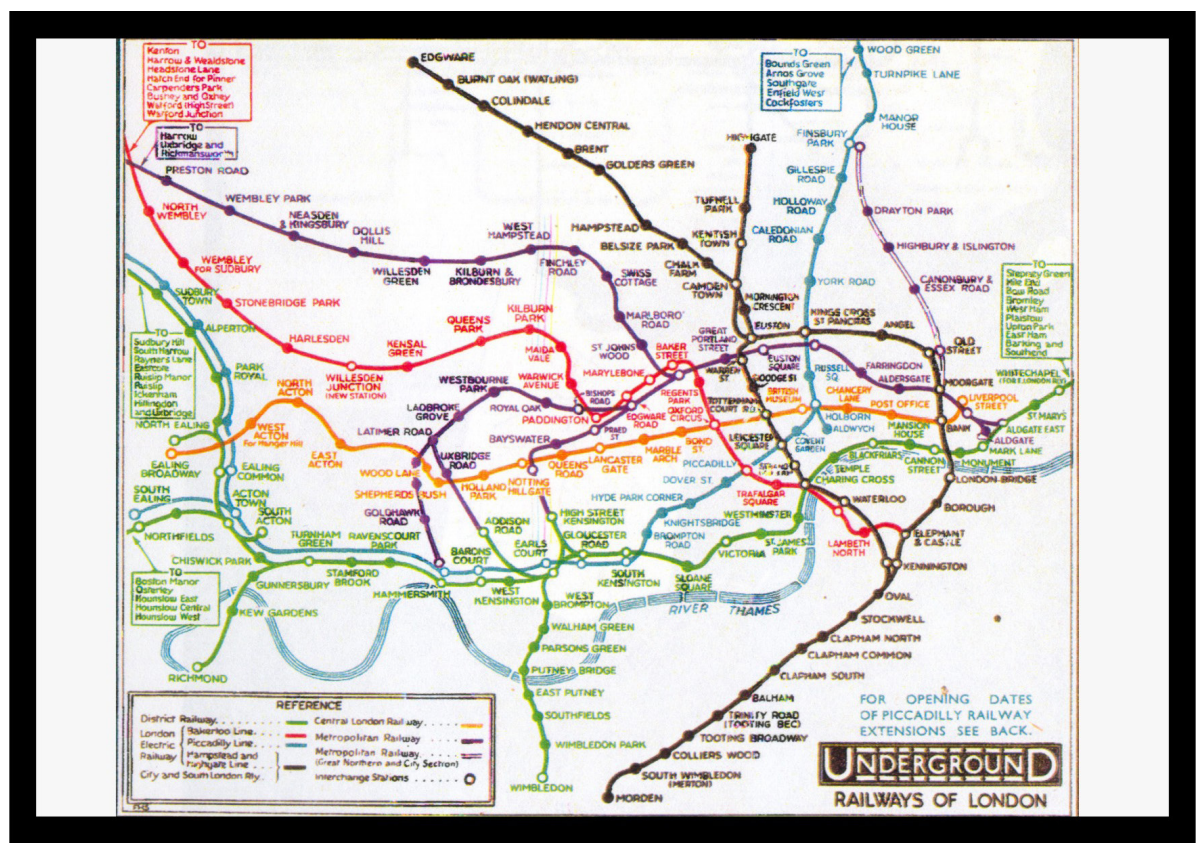

Figura 2 Mapa do metrô de Londres na edição de 1932, projeto de H.Stingemore, desenhista ("draughtsman") do Underground Group: representação cartográfica (já iniciando processo de simplificação). Fonte: Mr. Beck’s Underground Map, p.13

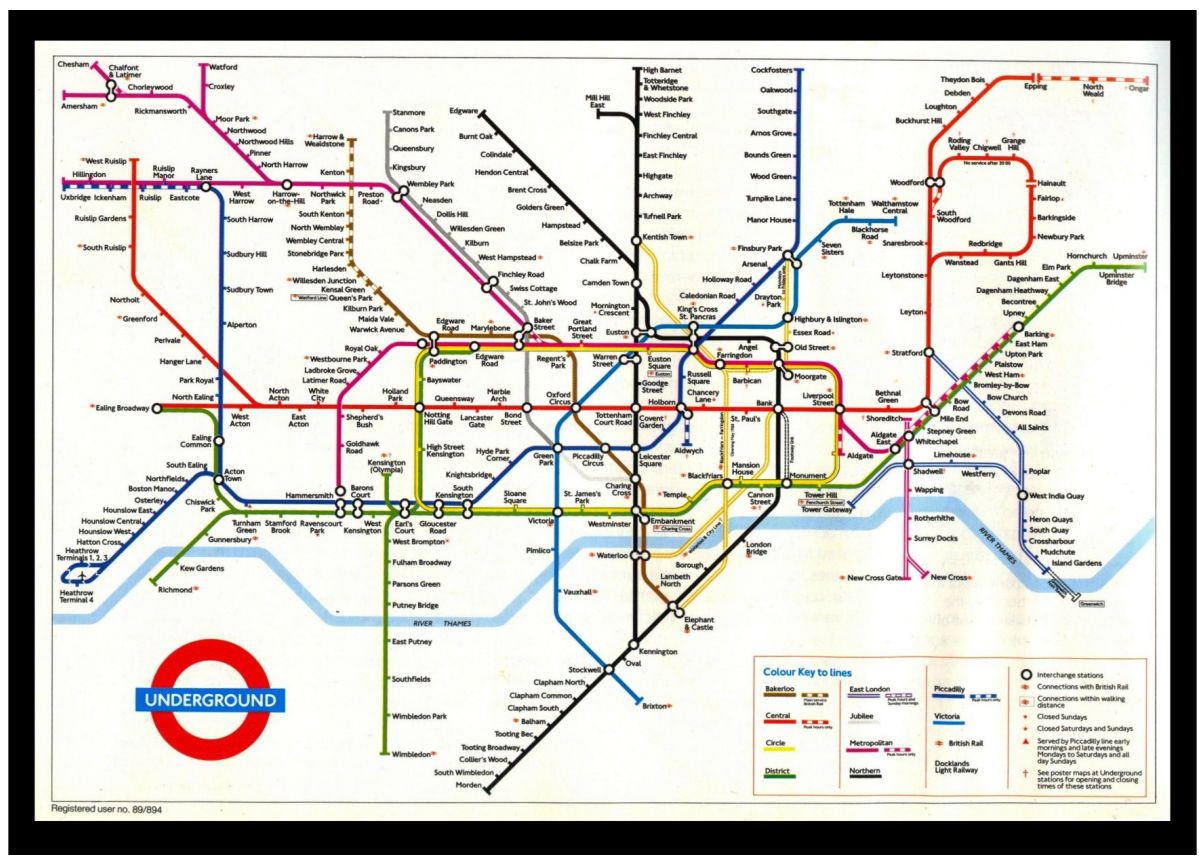

Figura 3 Mapa do metrô de Londres na edição dos anos 1980, conforme o projeto original de 1931 lançado em 1933, de autoria de Harry Beck, desenhista de engenharia ("engineering draughtsman") da London Transport: representação diagramática modular, baseada em 4 direções e 8 sentidos, estabelecidos pela Rosa dos Ventos. Fonte: Information Graphics, p.90 


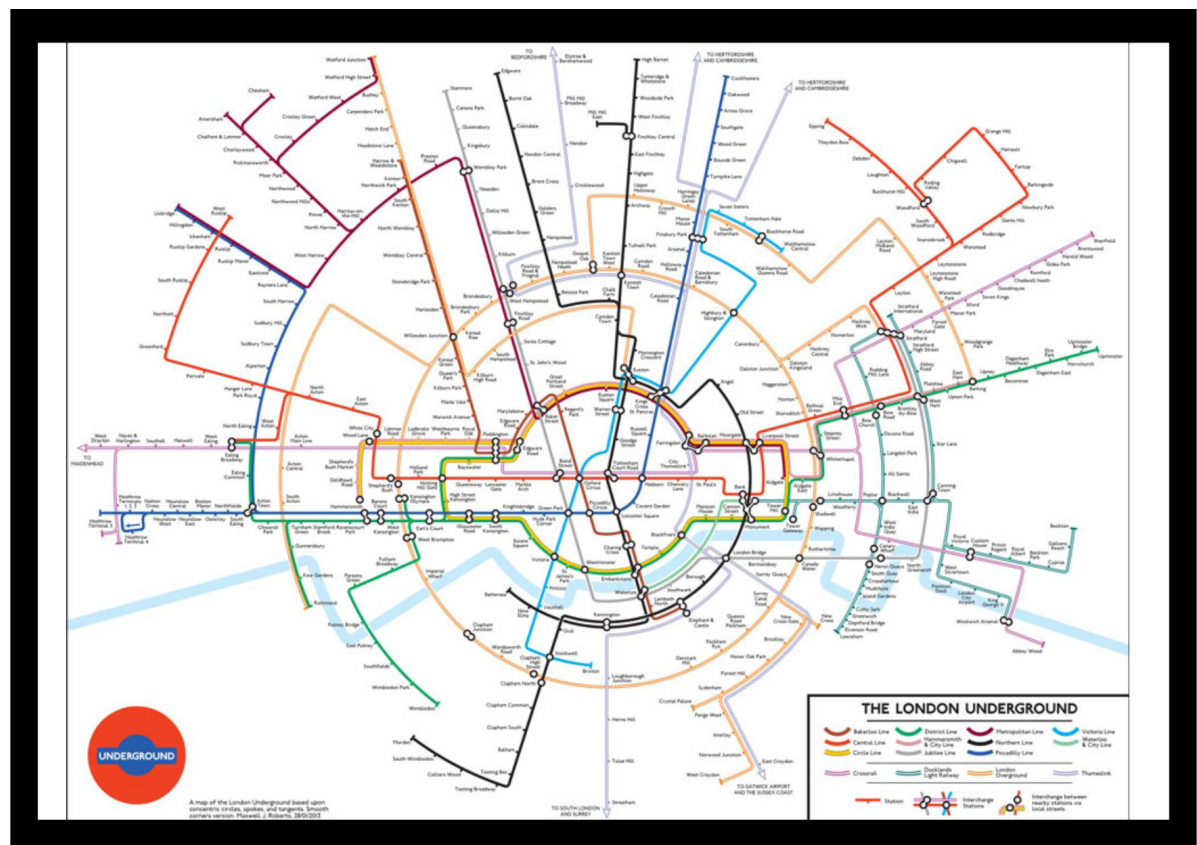

Figura 4 Mapa do metrô de Londres, projeto de Maxwell J. Roberts, professor de psicologia ("lecturer in psychology") na Universidade de Essex, publicado em 2013: representação diagramática modular, baseada na estrutura radial. Fonte: Going round in circles: the New York subway map redesigned (The Guardian).

\section{Análise}

1. O sistema radial pode ser adequado a uma determinada planta urbana, e não ser a outra. O sistema cardeal vem se mostrando adequado a qualquer planta.

2. O sistema cardeal segue o código mais universal de orientação geográfica criado pela humanidade: a Rosa dos Ventos.

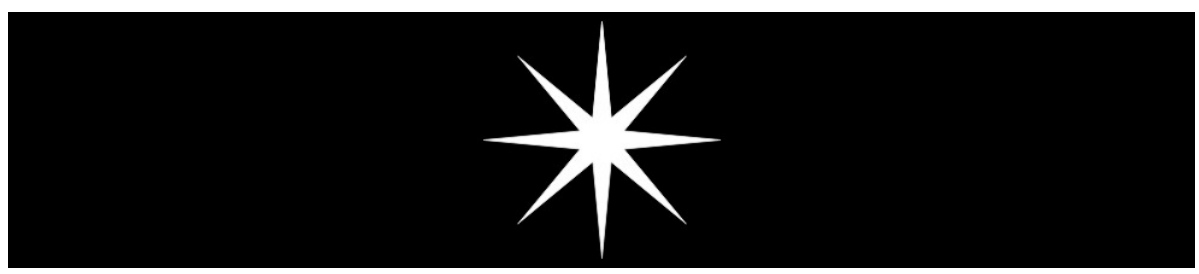

Figura 5 Rosa dos Ventos

3. A rede metroviária londrina explicita a universalidade deste código ao nomear os sentidos das linhas como Northbound, Southbound, Eastbound, Westbound - o que é melhor do que se utilizar para isso o nome da estação final da linha (como em Paris), porque todas as vezes que a linha é ampliada esta informação tem que ser trocada, tanto fisicamente, em todo o sistema (nas estações, nos trens, nos impressos e na internet), quanto mentalmente, na memória de todos os usuários. 


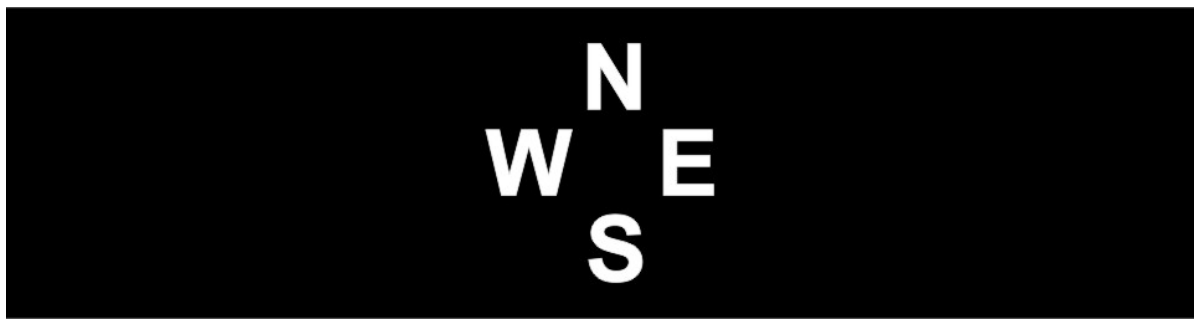

Figura 6 Sentidos das linhas: Northbound, Southbound, Eastbound, Westbound

4. Além disso, a cardinalidade do sistema metroviário londrino é integrada à comunicação pública da cidade em geral, presente inclusive nas placas de identificação de ruas. A integração de diferentes conteúdos num mesmo código, criando uma linguagem de orientação urbana única para todos os usuários da Cidade, habitantes e visitantes, é altamente benéfica dos pontos de vista operacional, econômico e social.

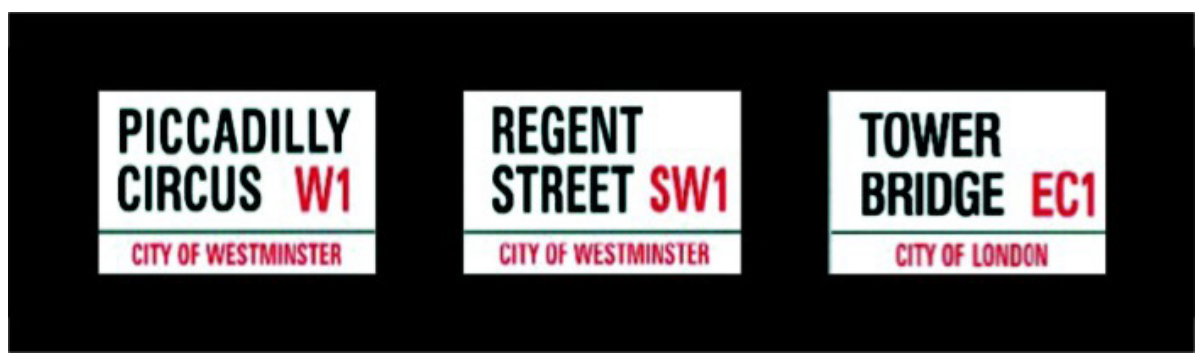

Figura 7 Placa de Rua de Londres: integração de diferentes conteúdos no mesmo código, abrangendo o sistema de informação metroviária e o código postal da cidade.

5. Ao menos para a planta londrina, o sistema radial exige mais espaço, como se vê nas ilustrações adiante (Figuras 11 e 12, onde se nota que as letras do sistema radial são menores do que as dos outros sistemas). Ocupar menos espaço com a informação só traz vantagens, porque permite:

1o: aumentá-la, o que resulta em melhor legibilidade, maior distância e maior campo de leitura (valores operacionais);

$\mathbf{2}^{\mathbf{0}}$ : com isso, oferecê-la simultaneamente a um número maior de pessoas (valor social);

$3^{\mathbf{0}}$ : reduzir o tamanho do suporte, se isso for conveniente (valor econômico);

$\mathbf{4}^{\mathbf{0}}$ : aumentar a quantidade de informação do objeto, quando for preciso (valor informativo).

Em Design de Informação, espaço vale ouro. 
6. As linhas retas do sistema cardeal são mais comuns nos percursos urbanos do que as grandes curvas ilustradas no sistema radial. Ao separar as linhas do Diagrama em dois tipos de configuração -reta e circular- não estamos contribuindo para visualizar o seu conteúdo, porque isso não corresponde à realidade.

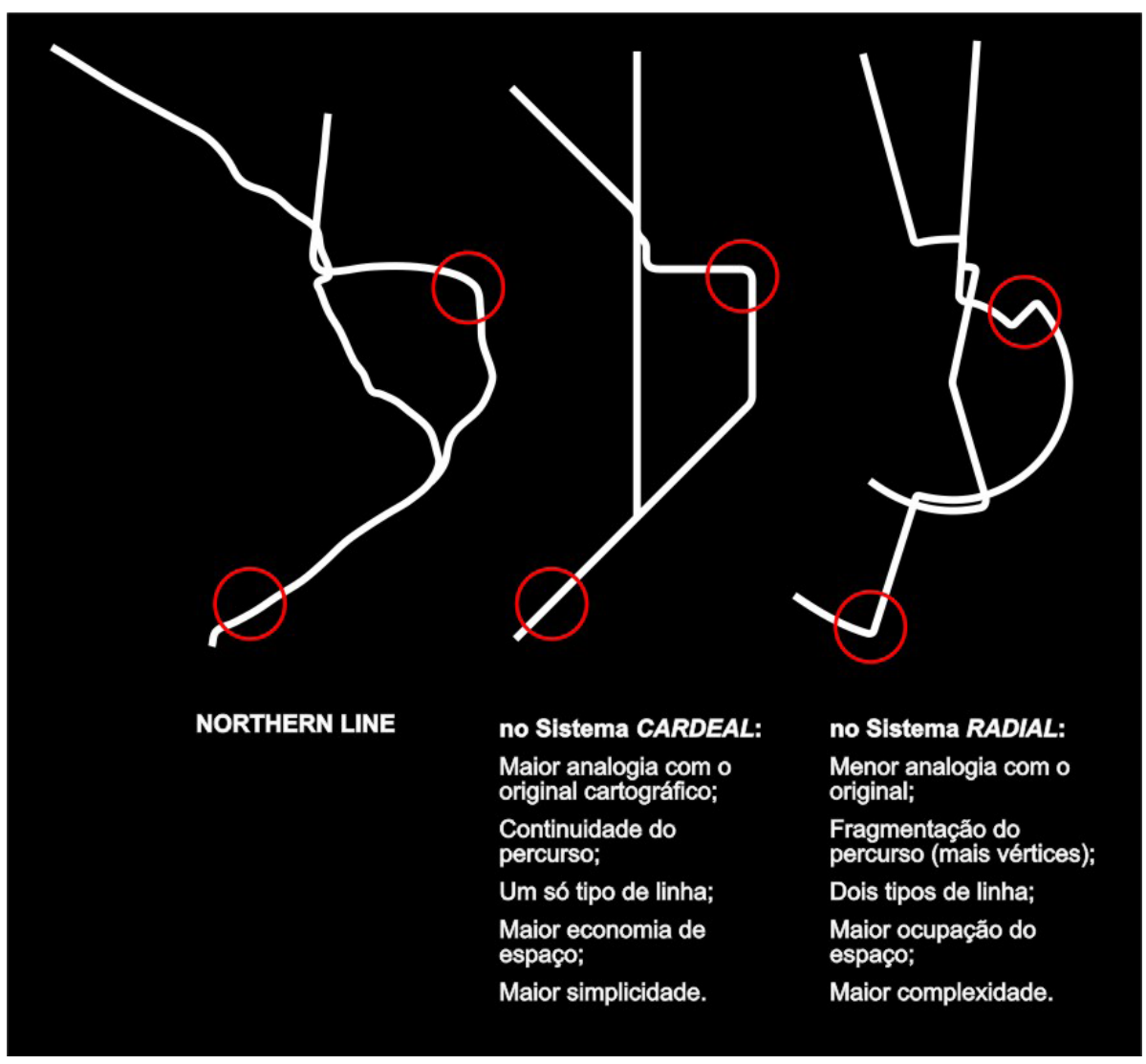

Figura 8 Comparativo dos três sistemas aplicados numa linha isolada: Northern Line 


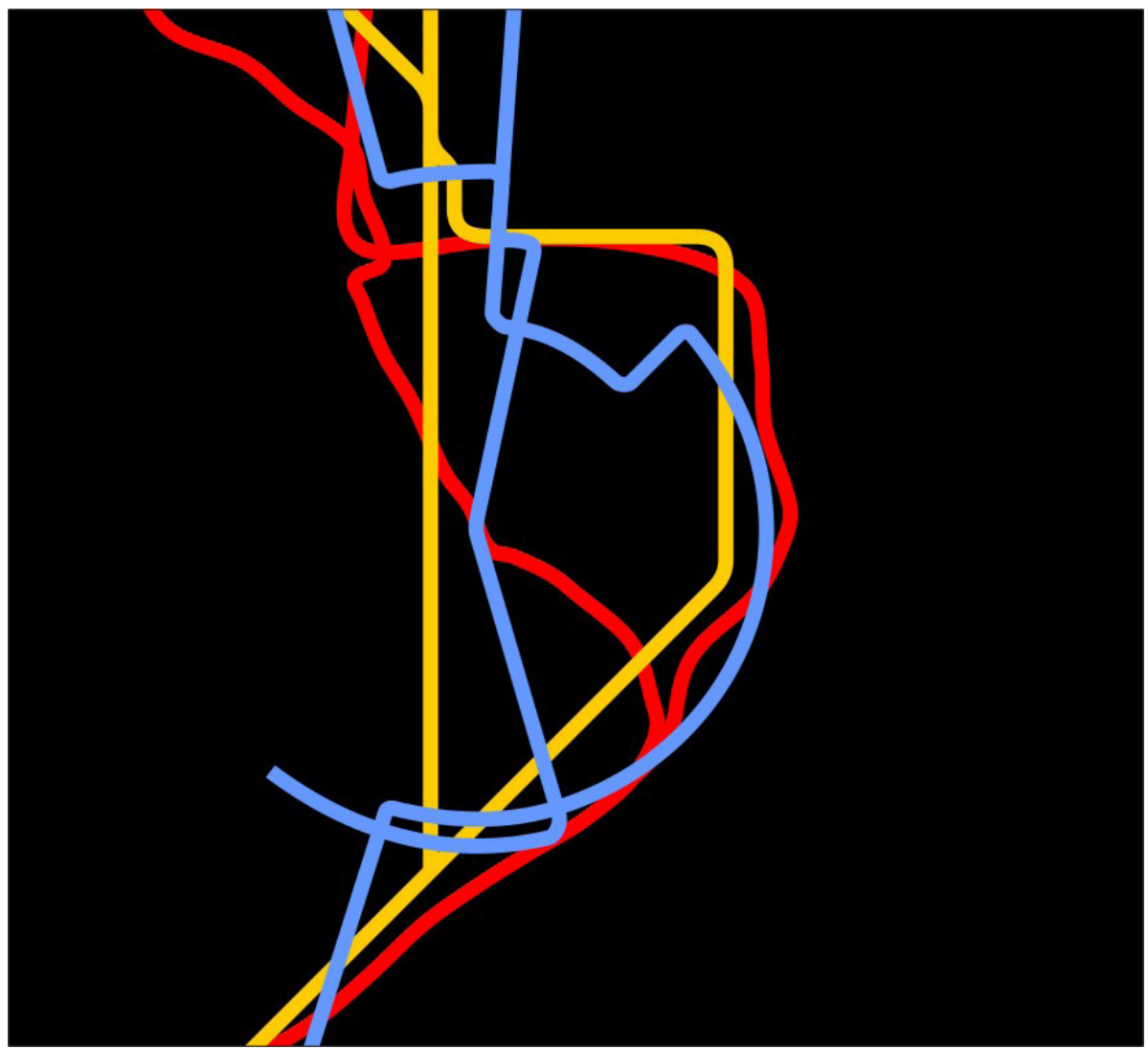

Figura 9 Figura 9 - Superposição dos três sistemas aplicados na Linha Northern: Mesmo com os três desenhos superpostos, pode-se reconhecer maior simplicidade no sistema cardeal (em amarelo, sendo azul para o sistema radial e vermelho para o cartográfico) e maior analogia entre ele e o original cartográfico.

7. Para conjugar esses dois tipos de linha (retas e circulares) o sistema radial demanda mudanças de direção, ou a ocorrência de vértices, que, além de inexistentes na realidade, são desnecessários no sistema cardeal. (Figura 8, trechos assinalados em vermelho)

8. As mudanças de direção no sistema cardeal são mais suaves que no sistema radial. Seguir o percurso de uma linha com o olho (eventualmente com a ajuda do dedo) é mais fácil no sistema cardeal. (Figura 8)

9. Observando-se comparativamente as estruturas gráficas desses três mapas dois a dois, ressalta ao olho a analogia entre o original cartográfico e o diagrama de Beck. 


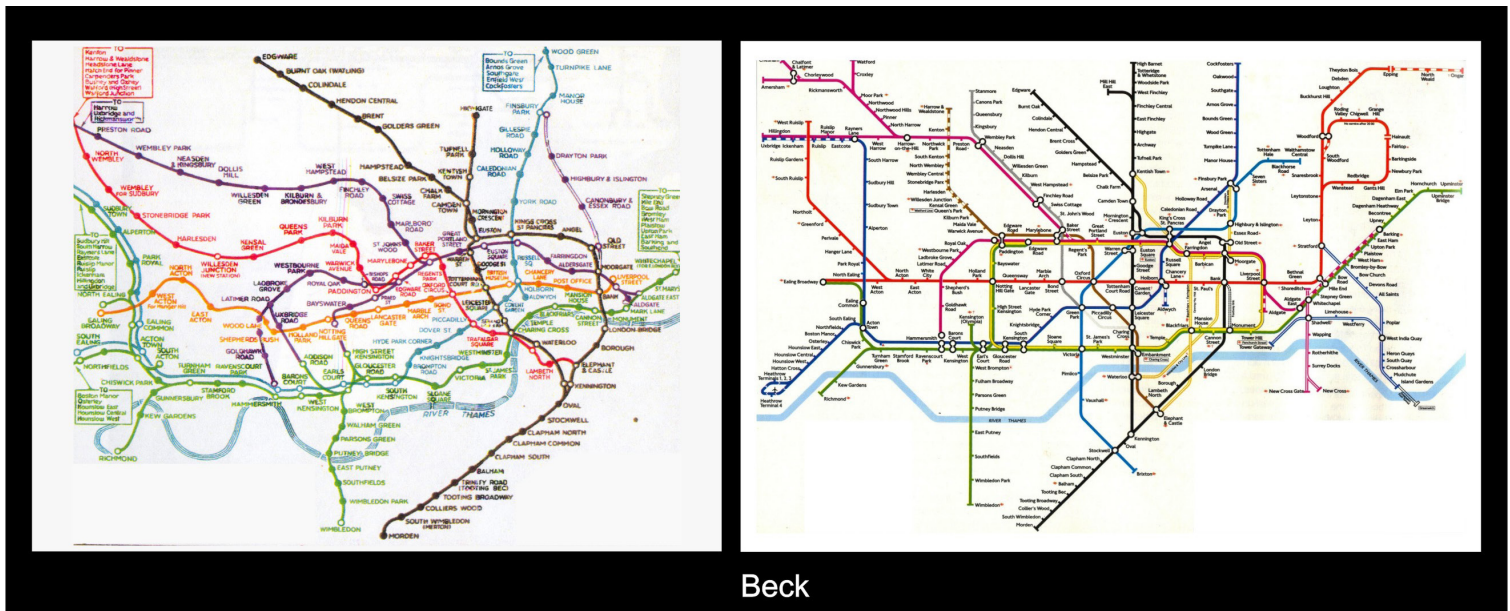

Figura 10 Comparativo entre os sistemas Cartográfico x Cardeal

Já o diagrama radial não apresenta a mesma semelhança, nem com o de Beck...

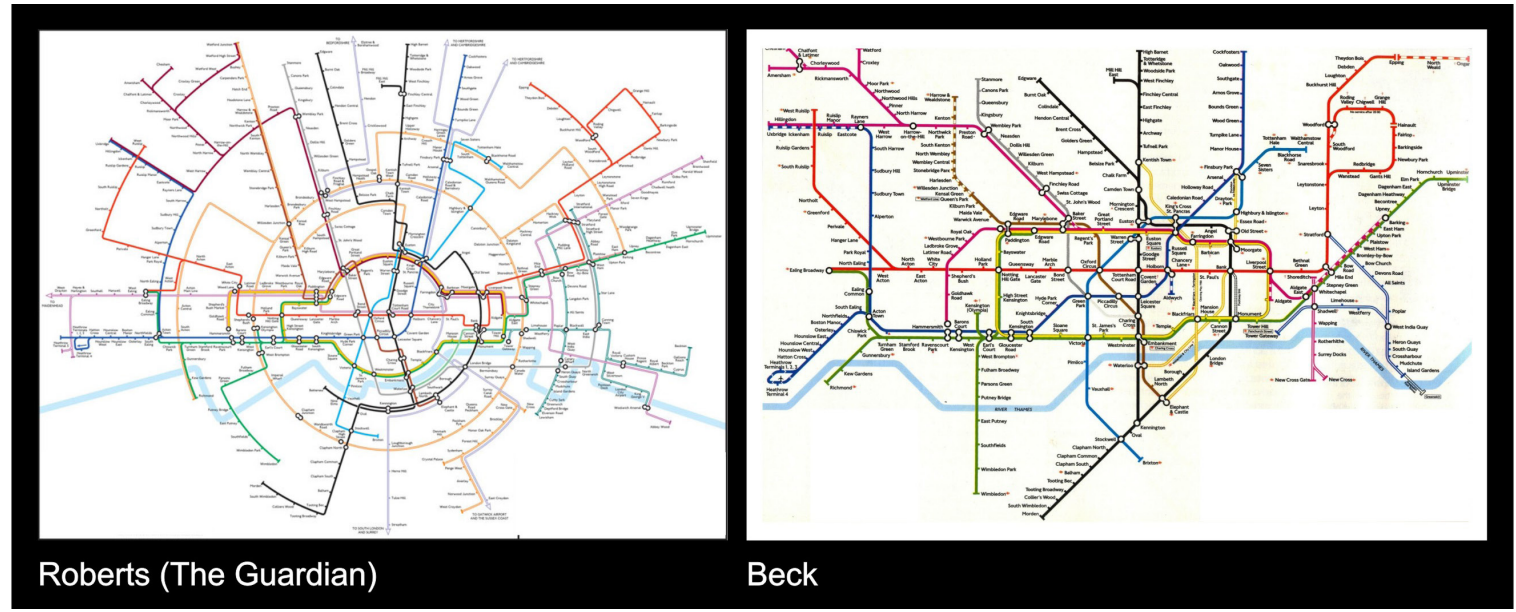

Figura 11 Comparativo entre os sistemas Radial x Cardeal

... nem com a estrutura cartográfica.

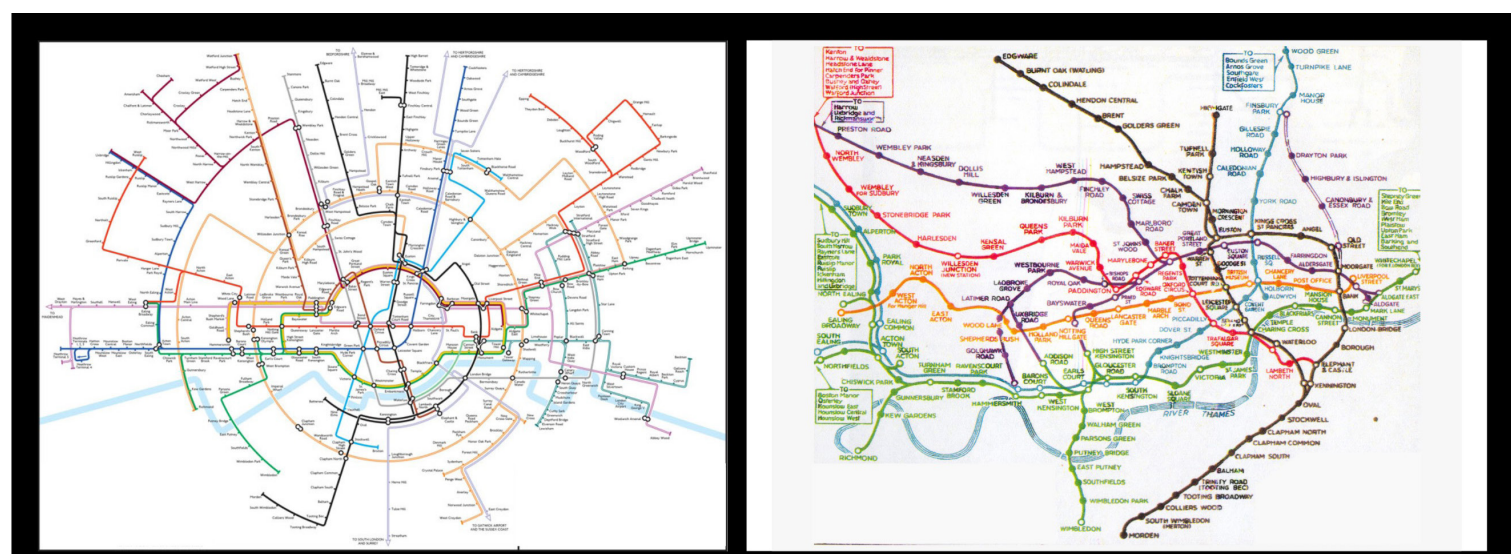

Roberts (The Guardian)

Figura 12 Comparativo entre os sistemas Radial x Cartográfico 
10. A hipotética utilização da estrutura radial para qualquer cidade, como sugere Roberts, aproxima muito as imagens de todas elas, não aproveitando a gestalt única de cada uma e sua identidade própria como fator de reconhecimento. Talvez somente as cidades marinhas escapem desse risco pelo seu perfil costeiro diferenciado.

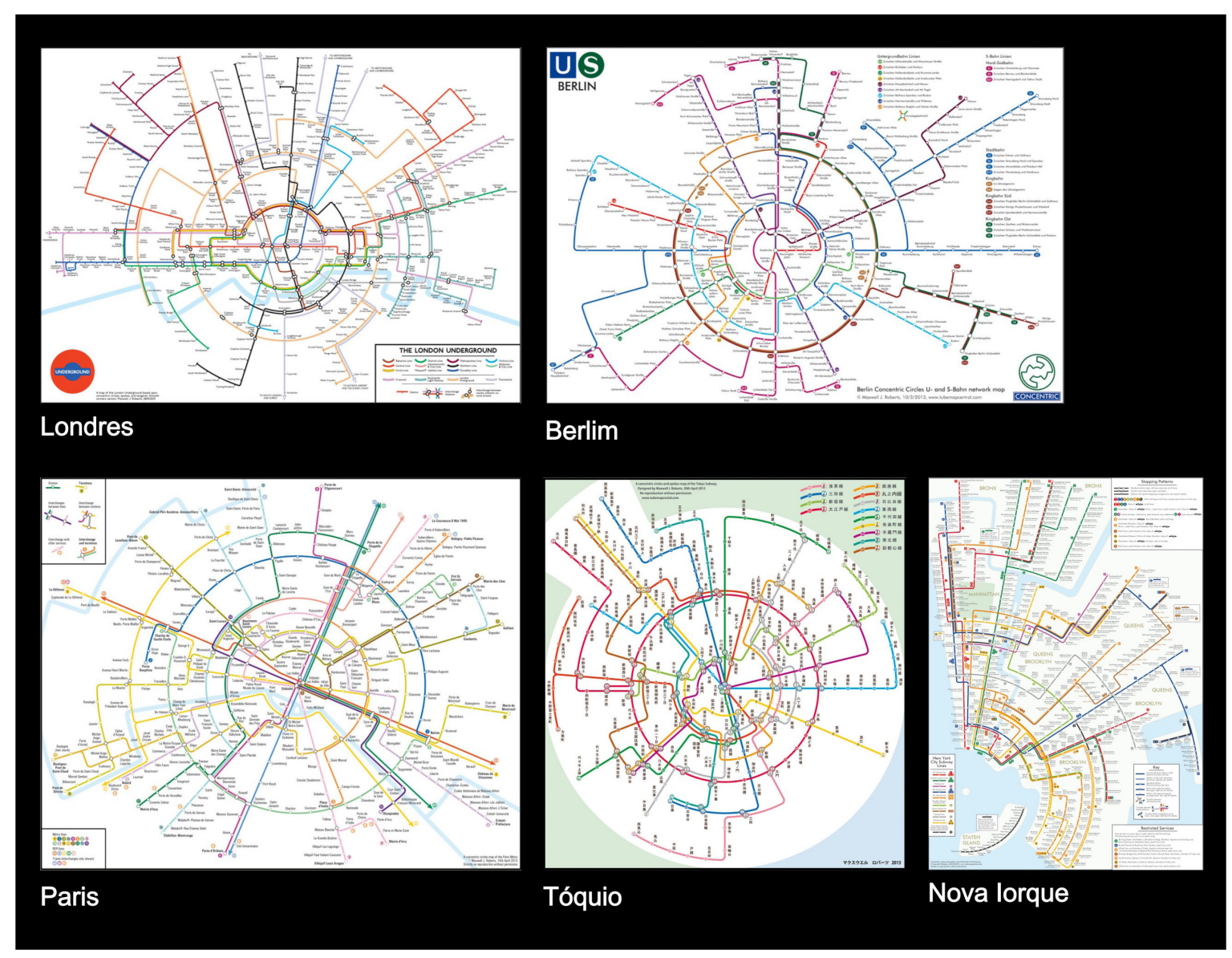

Figura 13 Comparativo entre os sistemas Radial x Cartográfico

11. No documento publicado pelo The Guardian na internet (ver Referências) não está explicitada a razão do sistema radial, por isso atribuo seu valor ao caráter experimental, enquanto não se encontra sua aplicabilidade.

\section{Digital X Analógico: Convenção X Representação}

Observar a relação entre os conceitos digital x analógico pode nos ajudar nesta análise - assim como em qualquer outro caso do design de informação.

Vivemos na era da digitalização generalizada. Não há parte da vida material contemporânea que ainda não seja regulada por equipamentos eletrônicos, chamados digitais. 
Depois de buscar a origem técnica desses termos (OLIVEIRA 2014), veremos o que eles significam para o design:

A tecnologia eletrônica é chamada de digital porque o sinal que transmite seus comandos é traduzido pelo computador numa seqüência de dígitos 1 e o, que correspondem respectivamente aos dois estágios possíveis do sinal, ligado e desligado. Qualquer informação ou forma recebida pela máquina será transformada numa seqüência (irregular) de sinais ligado/desligado, ou de dígitos 1/o (exemplo: 10100010100111), que por sua vez será transformada numa combinação de luzes na tela (pixels), configurando para nós as mensagens e imagens, codificadas pelo sistema. O sinal digital é portanto estável e intermitente.

Já o sinal chamado analógico é instável e contínuo, variando gradualmente de intensidade conforme a variação do seu conteúdo - como a coluna de um termômetro, que cresce ou decresce acompanhando a variação da temperatura do ambiente onde está instalada, refletindo essa realidade.

Pensando no usuário, e portanto no design, o termo digital está relacionado à possibilidade de controle do equipamento com as pontas dos dedos (ações leves e delicadas, das quais o touchscreen é o maior exemplo), ao contrário dos artefatos analógicos, que demandam também outras partes do corpo (mãos, braços, e até pernas, no caso dos pedais), exigindo maior esforço físico do operador. Os comandos eletrônicos por movimento do corpo também considero analógicos, na sua interface com o usuário.

Há ainda que se levar em conta a relação entre a letra e o dedo (origem da palavra dígito), provavelmente advinda da datilografia, hoje chamada de digitação.

Mas, na dicotomia digital $X$ analógico, a questão mais importante para o design é que, do ponto de vista do processo de leitura -não da tecnologia-, o design de informação deve buscar formas de comunicação o mais possível analógicas (utilizando imagens que estabeleçam algum tipo de analogia com a realidade), deixando as formas digitais (sinais convencionados, tendentes ao abstrato) somente para quando forem necessárias, ou mais eficazes.

A comunicação visual analógica não prescinde, entretanto, da tecnologia digital, nem esta prescinde daquela, na sua interface com o usuário - considere os milhares de ícones que identificam as ferramentas dos softwares que usamos no dia a dia, ou os comandos por movimento, entre muitos exemplos. Sob o ponto de vista do design, ao menos, essa dicotomia não é uma oposição, como parece ser hoje em outros campos da vida material, mas, ao contrário, oferece interessantes possibilidades de integração.

Do analógico $\mathrm{X}$ digital, passamos ao analógico + digital.

Veja, por exemplo, os relógios eletrônicos de leitura analógica: seu painel LCD mostra ponteiros girando, que na verdade são luzes acendendo e apagando para simular o tradicional giro mecânico das agulhas, que por sua vez estabelece uma analogia com o movimento 
rotacional do sistema solar, principal referência para a nossa compreensão do fenômeno do tempo, e de sua forma de medição. Neste caso a tecnologia é digital, mas a leitura, analógica.

A diferença é que o painel digital você lê, e o analógico você vê que é outra forma de ler, porém muito mais rápida.

O problema das bulas de remédio é que são totalmente digitais, no sentido de que sua imagem não reflete seu conteúdo, mas reduz-se a uma seqüência modulada e homogênea de dígitos convencionados (alfanuméricos, no caso) que o interpretam, e que dependem de decodificação para seu entendimento (leitura).

Para facilitar a compreensão e memorização de suas mensagens elas deveriam, porém, ser também analógicas, ou heterogêneas, usando, por exemplo, variações significativas de tamanho de letra, conforme a importância do assunto, ou usando cores (por exemplo, vermelho para contra-indicações e verde para modo de usar), ou também elementos figurativos, como símbolos ou diagramas, para mostrar o que querem dizer.

\section{Conclusão}

A cartografia radial de Max Roberts também se baseia numa convenção visual (a partir da radialidade estrutural das cidades, com suas conexões centro < periferia), mais do que na sua relação com a forma da cidade em questão. À primeira vista, a estrutura radial parece igualar todos os mapas - como a estrutura tipográfica (composição e diagramação) iguala todas as páginas de um livro, embora elas contenham textos diferentes (diferentes seqüências de sinais ou dígitos).

Já o sistema cardeal de Harry Beck se baseia numa analogia geográfica ou cartográfica, ao sintetizar visualmente (em apenas 4 direções!) uma forma pré-existente: a forma (natural e construída) da cidade. Há certo grau de digitalização ou homogeneização no seu mapa, por exemplo, na eqüidistância entre as estações, que não corresponde à realidade, mas isso faz parte de sua proposta de síntese. A estrutura básica de seu mapa, entretanto, é calcada na estrutura da cidade de Londres e sua rede de transporte subterrâneo. Se não bastasse a comparação visual (oferecida acima) para confirmar esta hipótese, quem já usou esse sistema londrino (o mapa, o metrô e a cidade) pode comprová-la.

O primeiro sistema mostra grande parte dos nossos trajetos como circulares, circundantes ao centro urbano, cruzando os eixos que levam até ele (em ângulos variados). Mas nossos caminhos (sejam transversais, longitudinais ou diagonais), são primordialmente retilíneos (por trecho), como interpretou o segundo, e assim são memorizados por nós, mesmo quando curvos (fora situações especiais, como rótulas e trevos). Num espaço sem referências externas, como 
o do metrô, as curvas dos trajetos são ainda menos perceptíveis pelos passageiros.

No sistema de Beck, uma linha em torno do Hyde Park em Londres será um retângulo horizontal, e em torno do Central Park de Nova York será um retângulo verticalizado. No de Roberts, ambos serão circulares.

O ideal para os produtos do design de informação é uma mistura de ambas as linguagens, analógica e digital. Mas, nessa mistura, geralmente prevalece a primeira.

Por essas e outras razões, há muitas décadas o sistema beckiano vem se adaptando a qualquer cidade, de diferentes tamanhos e configurações, no Ocidente e no Oriente, no Hemisfério Norte ou no Sul, em países de diferentes línguas, culturas, e até escritas - de São Paulo a Tóquio.

Sua disseminação, porém, não nos exime -ao contrário- de experimentar-lhe alternativas. Dada a complexidade do tema (oriunda da complexidade da rede de transporte e suas possibilidades de trajetos e conexões), a tarefa é árdua, exigindo esforços extensivos e sistemáticos para se alcançar novas descobertas!

O trabalho de Max Roberts representa um grande passo nesse sentido, demonstrando, por sua extensão e profundidade, consciência sobre a escala da tarefa, além de disposição e disponibilidade para enfrentá-la.

\section{Agradecimento}

Agradeço especialmente ao Professor André Monat a proposta temática, os diálogos sobre o tema, e o estímulo ao meu trabalho e a esta publicação. Agradeço também a Max Roberts a gentileza de autorizar o uso das imagens publicadas no The Guardian.

\section{Referências}

GARLAND, K. 1994. Mr. Beck's Underground Map. Middlessex: Capital Transport Publication

OLIVEIRA, R. C. Sinal Analógico X Sinal Digital

https://www.youtube.com/watch?v=i_Y8Tya_qf8 - acesso 13.12.2014, 03h50 Joaquim Redig | Beck x Roberts: Comparativos do Diagrama do Metrô de Londres ROBERTS, M. 2012. Going round in circles: the New York subway map redesigned. http://www.theguardian.com/news/datablog/2013/aug/15/going-roundcircles-new-york-subway- map-redesigned - acesso 9.9.13 $15 \mathrm{~h} 30$ WILbUR, P. 1989. Information Graphics. Londres: Trefoil PublicationsSergio R. Gurski 


\section{Sobre o autor}

\section{Joaquim Redig}

Bacharel, mestre e doutorando em Design pela ESDI, Escola Superior de Desenho Industrial da Universidade do Estado do Rio de Janeiro, Professor da PUC-Rio, Pontifícia Universidade Católica do Rio de Janeiro. Professor Visitante na Universidad Católica de Chile. Diretor Técnico do escritório Aloisio Magalhães. Co-fundador da PVDI. Titular do escritório Design Redig. Atuante em Design Industrial e Gráfico. Autor de "Sobre Desenho Industrial" ed. ESDI/UniRitter, "Sentido do Design” ed. Imprinta, “No Mínimo” ed. UFSM, "Nossa Bandeira” ed. Fraiha. Prêmios Lucio Meira, CNPq/Fiesp, IAB-RJ, Bienal Brasileira Design, Mexinox, MCB/Brasil Faz Design, Popai, MCB/Textos. <designredig@alternex.com.br>

Artigo recebido em 15 out. 2014, aprovado em 19 dez. 2014. 